\title{
Observations on the treatment of rheumatoid disease with penicillamine
}

\author{
JOHN R. GOLDING \\ D.M., M.R.C.P.
}

Consultant Physician

\author{
J. V. WILSON \\ M.D., F.R.C.P. \\ Consultant Pathologist
}

\author{
Albert T. DAY \\ M.B., Ch.B., D.Obst., R.C.O.G. \\ Clinical Assistant \\ Royal Bath Hospital, Harrogate
}

\begin{abstract}
ব
Summary

Forty-five patients with severe rheumatoid arthritis were given D-penicillamine hydrochloride according to a fixed regimen for up to 2 years. The effects of treatment were observed both clinically and by the use of laboratory parameters.

The results show that about $75 \%$ of patients exhibited objective improvement. Those with rheumatoid arthritis were found to do particularly well. The incidence, type and severity of side-effects are discussed.
\end{abstract}

The evaluation of a drug said to act long-term in rheumatoid arthritis is one of the most difficult exercises in clinical medicine. Preparations of gold have been used for years (Hartfall, Garland \& Goldie, 1937) but it was not until a double-blind controlled trial (Annals of Rheumatic Diseases, 1962) that its effect was definitely established.

Despite the wide range of anti-rheumatic agents at our disposal and the judicious use of rest and graded exercises there remains, unfortunately, a sizeable group of patients in whom conventional therapy does not seem to have improved their situation significantly. It is to these patients that our attentions have been directed.

Deutsch \& Morton (1957) succeeded in dissociating macroglobulins with penicillamine; Griffen et al. (1960) and Dressner \& Trombly (1960) applied this knowledge to the levels of rheumatoid factor and described how the titre could be lowered by the use of this drug.

The laboratory investigations on a group of patients suffering from rheumatoid arthritis were of interest but, during the course of these investigations, the patients began to volunteer comments on spontaneous improvements in their clinical condition and, therefore, Jaffe (1965) began an investiga- tion into the clinical effects of penicillamine in rheumatoid arthritis.

Our present communication is about work done in Harrogate in this connection since 1967, a preliminary report on laboratory investigations of rheumatoid patients giving slight encouragement (Golding, Wilson \& Plunkett, 1968).

The initial aim was to use the drug in patients who had not responded to the normal regimen of treatment and then to examine the results critically to determine whether a formal double-blind trial should be undertaken. These patients had been under the care of a specialist unit for some timein some cases, years-prior to the exhibition of the drug and, therefore, to some extent serve as their own control.

Experience gained in dealing with these patients has been invaluable during the planning of the double-blind trial which has now been in progress for some 12 months and the results of which will be communicated at a later date.

\section{Materials and methods}

Patients admitted to this trial all satisfied the ARA requirements as either definite or classical rheumatoid arthritics; they had all had rheumatoid arthritis for sufficiently long to enable the wellestablished form of treatment-gold, anti-malarials, aspirin, corticosteroids - to be tried and abandoned as either of no benefit or producing undesirable effects (e.g. rash with myocrisin, etc.). All the patients had laboratory evidence and/or clinical evidence of continuing activity of the disease and could be considered to be going downhill because of it. All were informed that penicillamine was of no proven use in rheumatoid arthritis and might be dangerous; all patients were eager to try it.

They comprised forty-five patients: twelve males 
and thirty-three females, their ages ranging from 32 years to 76 years (five premenopausal). The average length of time the patients had had rheumatoid arthritis was 10 years (scatter of 1 year to 40 years).

All patients were admitted to hospital for institution of the drug and a careful check made to ensure that there were no signs of bone-marrow depression or albuminuria. The regimen started with $1 \times 150$ $\mathrm{mg}$ capsule of penicillamine $\mathrm{HCl}$ q.d.s. and was increased to $600 \mathrm{mg}$ q.d.s. by weekly increments of $600 \mathrm{mg}$. Examinations of the blood and urine were made weekly during the first month then at monthly intervals to exclude signs of bone-marrow depression or albuminuria. Additional investigations (blood urea, haemoglobin, ESR and Rose-Waaler) as well as subjective and objective assessments made by a clinician and occupational therapist, were performed at monthly intervals. Side-effects were noted, as was the total spectrum of drugs and any changes in it, with particular accord to analgesic requirements and the amount of steroid taken. Finally, an estimate of the duration of early morning stiffness made by each patient at each visit was recorded.

Some months after the investigation was commenced the maximum dose of penicillamine was reduced to $300 \mathrm{mg}$ q.d.s. because it became evident that most side-effects occurred above this dose and, at that time, our impression was that no clinical deterioration resulted from the reduction.

Work on the antipyridoxine effect of penicillamine (Asatoor, 1964; Jaffe, Altman \& Merryman, 1964) suggested that a prophylactic dose of pyridoxine might prevent long-term vitamin $B_{6}$ deficiency but, after 16 months, further evidence (Jaffe, personal communication) showed that no deficiency occurred even after prolonged exhibition of penicillamine and pyridoxine was withdrawn from the regimen.
The results are shown below. It will be seen that a relatively common early side-effect was loss of taste. Work by Jaffe (1968) on the effects of penicillamine on the kidney and on taste suggested that a small dose of copper sulphate (5 mg daily) might avoid this impairment of taste and it was decided to add this to our regimen, all patients having taken $5 \mathrm{mg}$ daily during the past 7 months.

\section{Results}

This is a potent preparation being used in the treatment of a non-fatal disease; therefore, it is of some relevance to state that no patient has died or is worse as a result of the use of penicillamine. The assessment of the efficacy of any agent in the treatment of a disease which remits as part of its natural history is notoriously difficult. We have followed the course of each patient from as many objective points of view as possible, noting any change in his functional grading, any measurable change in vascular lesions and recording the laboratory parameters previously mentioned.

A table of the erythrocyte sedimentation rate (Westergren) is shown (Table 1) for each patient at quarterly intervals. In two cases $(4 \%)$ the final result was higher than the initial reading; in sixteen patients $(35 \%)$ there was no real change, while in the remaining twenty-eight patients $(61 \%)$ the ESR fell. The results are interpreted graphically (Fig. 1) as the percentage change in ESR of each figure against its original which we have called $100 \%$.

Table 2 deals with the Rose-Waaler test. The technique for these tests was standard and they were performed under constant conditions by the same technician. There was no predictable pattern of results except that no final reading was higher than the initial one. Twenty-four patients had a final dilution result at least two tubes less than the original

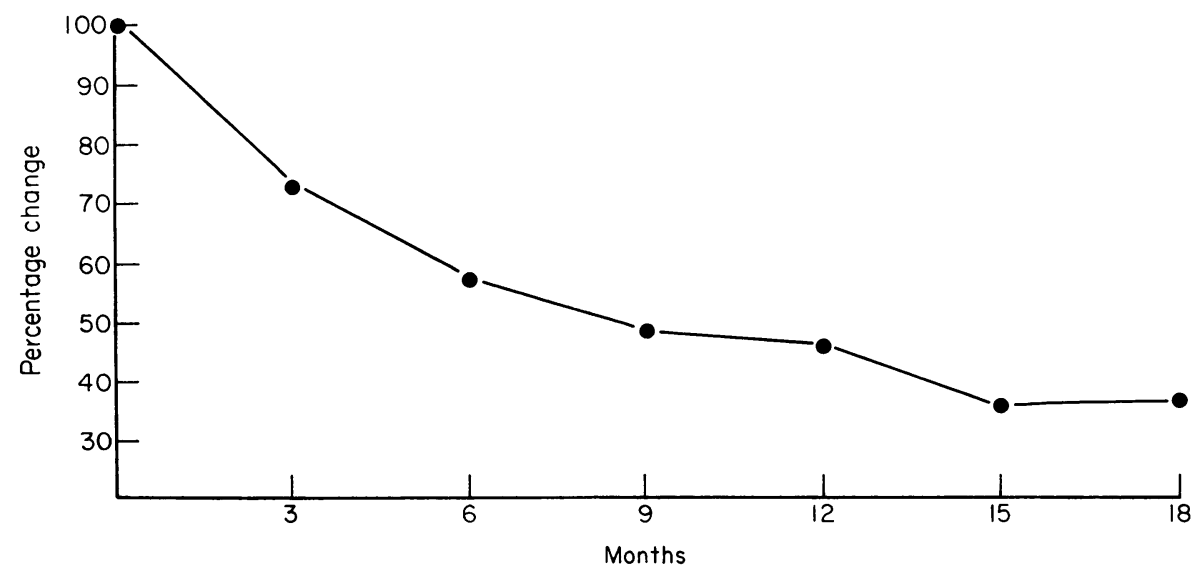

FIG. 1. Mean percentage change in ESR/months. 


\begin{tabular}{|c|c|c|c|c|c|c|c|c|c|c|c|c|c|c|c|c|c|c|c|c|c|c|c|c|c|c|c|}
\hline \multirow{2}{*}{\multicolumn{2}{|c|}{ No. Sex }} & \multirow[b]{2}{*}{ Age } & \multirow{2}{*}{$\begin{array}{c}\text { Years } \\
\text { of } \\
\text { RA }\end{array}$} & \multicolumn{8}{|c|}{ 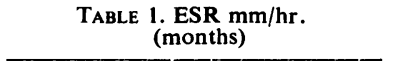 } & \multicolumn{8}{|c|}{$\begin{array}{l}\text { TABLE 2. Rose-Waaler, 1: } \\
\text { (months) }\end{array}$} & \multicolumn{8}{|c|}{ TABLE 3. $\mathrm{Hb} \%(100 \%=14.8 \mathrm{~g} \%)$} \\
\hline & & & & 0 & 3 & 6 & 9 & 12 & 15 & 18 & 21 & 0 & 3 & 6 & 9 & 12 & 15 & 18 & 21 & 0 & 3 & 6 & 9 & 12 & 15 & 18 & 21 \\
\hline 1 & $\mathbf{F}$ & 46 & 12 & 33 & 10 & 13 & 9 & 5 & 7 & 7 & 2 & 512 & 1024 & 256 & 256 & 256 & 512 & 512 & 128 & 88 & 92 & 91 & 92 & 90 & 82 & 87 & 97 \\
\hline 2 & $\mathbf{F}$ & 45 & 10 & 106 & 116 & 37 & 40 & 21 & 6 & 5 & 31 & 64 & 32 & 16 & 16 & 32 & 32 & 8 & 2 & 80 & 90 & 91 & 102 & 94 & 92 & 95 & 94 \\
\hline 3 & $\mathbf{F}$ & 52 & 12 & 26 & 35 & 28 & 22 & 10 & 17 & 11 & 20 & 512 & 256 & 128 & 64 & 64 & 64 & 128 & 128 & 90 & 99 & 95 & 92 & 99 & 85 & 91 & 94 \\
\hline 4 & $\mathbf{F}$ & 54 & 5 & 52 & 56 & 27 & 18 & 22 & 20 & 50 & & 1024 & 256 & 256 & 256 & 256 & 256 & 256 & & 62 & 84 & 90 & 88 & 80 & 86 & 88 & \\
\hline 5 & $\mathbf{F}$ & 63 & 5 & 67 & 24 & 23 & 35 & 10 & 7 & 9 & & 512 & 32 & 2 & 64 & 2 & 2 & 2 & & 91 & 79 & 82 & 75 & 80 & 82 & 85 & \\
\hline 6 & $\mathbf{F}$ & 63 & 40 & 33 & 11 & 23 & 21 & 16 & 14 & & & 2048 & 256 & 128 & 128 & 64 & 64 & & & 86 & 80 & 87 & 84 & 80 & 87 & & \\
\hline 7 & $\mathbf{F}$ & 38 & 9 & 29 & 11 & 6 & 4 & 4 & 6 & & & 256 & 64 & 128 & 32 & 64 & 64 & & & 87 & 87 & 99 & 85 & 97 & 99 & & \\
\hline 8 & $\mathbf{F}$ & 51 & 4 & 29 & 30 & 15 & 21 & 7 & 17 & & & 512 & 256 & 512 & 1024 & 128 & 128 & & & 85 & 85 & 82 & 85 & 82 & 90 & & \\
\hline 9 & $\mathbf{F}$ & 57 & 4 & 53 & 20 & 11 & 8 & 7 & 1 & & & 512 & 256 & 128 & 64 & 32 & 32 & & & 86 & 94 & 102 & 97 & 103 & 95 & & \\
\hline 10 & $\mathbf{F}$ & 69 & 9 & 39 & 51 & 32 & 53 & 56 & 63 & & & 512 & 512 & 128 & 64 & 64 & 128 & & & 74 & 84 & 73 & 66 & 67 & 73 & & \\
\hline 11 & $\mathbf{F}$ & 56 & 6 & 8 & 6 & 4 & 5 & 5 & 13 & & & 128 & 32 & 2 & 2 & 2 & 2 & & & 94 & 97 & 93 & 91 & 99 & 97 & & \\
\hline 12 & $\mathbf{F}$ & 55 & 4 & 45 & 9 & 18 & 12 & 16 & 10 & & & 1024 & 256 & 512 & 512 & 64 & 256 & & & 99 & 98 & 99 & 90 & 101 & 95 & & \\
\hline 13 & $\mathbf{F}$ & 44 & 25 & 31 & 30 & 25 & 27 & 28 & & & & 2048 & 2048 & 2048 & 2048 & 1024 & & & & 86 & 95 & 103 & 94 & 102 & & & \\
\hline 14 & $\mathbf{M}$ & 63 & 16 & 37 & 44 & 39 & 33 & 38 & & & & 2048 & 1024 & 1024 & 1024 & 1024 & & & & 94 & 98 & 94 & 97 & 87 & & & \\
\hline 15 & $\mathbf{F}$ & 52 & 5 & 33 & 28 & 20 & 15 & 23 & & & & 256 & 256 & 256 & 32 & 32 & & & & 73 & 78 & 75 & 70 & & & & \\
\hline 16 & $\mathbf{F}$ & 38 & 2 & 50 & 31 & 38 & 41 & 52 & & & & 128 & 64 & 32 & 16 & 16 & & & & 72 & 80 & 75 & 74 & 84 & & & \\
\hline 17 & $\mathbf{F}$ & 54 & 9 & 44 & 20 & 8 & 10 & 6 & & & & 128 & 128 & 128 & 32 & 64 & & & & 90 & 98 & 86 & 88 & 92 & & & \\
\hline 18 & $\mathbf{M}$ & 53 & 3 & 88 & 72 & 55 & 28 & 10 & & & & 256 & 128 & 64 & 32 & 16 & & & & 66 & 67 & 87 & 90 & 99 & & & \\
\hline 19 & $\mathbf{F}$ & 71 & 18 & 30 & 8 & 2 & 10 & 14 & & & & 64 & 64 & 64 & 16 & 32 & & & & 82 & 87 & 90 & 88 & 93 & & & \\
\hline 20 & $\mathbf{M}$ & 62 & 20 & 15 & 4 & 6 & 2 & 4 & & & & 2 & 2 & 2 & 2 & 2 & & & & 91 & 102 & 98 & 95 & 93 & & & \\
\hline 21 & $\mathbf{F}$ & 66 & 16 & 43 & 5 & 7 & 16 & 30 & & & & 1024 & 256 & 128 & 64 & 64 & & & & 78 & 75 & 88 & 82 & 82 & & & \\
\hline 22 & $\mathbf{M}$ & 52 & 2 & 35 & 27 & 17 & 40 & 56 & & & & 512 & 512 & 512 & 512 & 512 & & & & 102 & 102 & 98 & 99 & 93 & & & \\
\hline 23 & $\mathbf{F}$ & 47 & 2 & 122 & 80 & 30 & 15 & 35 & & & & 256 & 512 & 128 & 128 & 64 & & & & 81 & 90 & 87 & 90 & 88 & & & \\
\hline 24 & $\mathbf{F}$ & 76 & 20 & 28 & 33 & 20 & 21 & 30 & & & & 32 & 32 & 32 & 64 & 32 & & & & 79 & 85 & 82 & 84 & 88 & & & \\
\hline 25 & $\mathbf{F}$ & 47 & 2 & 122 & 80 & 30 & 15 & 35 & & & & 256 & 512 & 128 & 128 & 64 & & & & 73 & 78 & 82 & 84 & & & & \\
\hline 26 & $\mathbf{F}$ & 71 & 14 & 37 & 18 & 31 & 30 & & & & & 64 & 64 & 2 & 2 & & & & & 68 & 82 & 80 & 80 & & & & \\
\hline 27 & $\mathbf{F}$ & 56 & 8 & 70 & 32 & 24 & 13 & & & & & 2 & 2 & 2 & 4 & & & & & 75 & 85 & 82 & 94 & & & & \\
\hline 28 & $\mathbf{F}$ & 53 & 10 & 40 & 36 & 5 & 6 & & & & & 256 & 256 & 64 & 64 & & & & & 72 & 72 & 75 & 76 & & & & \\
\hline 29 & $\mathbf{M}$ & 64 & 10 & 47 & 42 & 32 & 28 & & & & & 128 & 128 & 128 & 128 & & & & & 85 & 90 & 94 & 91 & & & & \\
\hline 30 & $\mathbf{F}$ & 45 & 3 & 15 & 7 & 8 & 10 & & & & & 2 & 2 & 2 & 2 & & & & & 82 & 82 & 94 & 82 & & & & \\
\hline 31 & $\mathbf{M}$ & 52 & 23 & 20 & 18 & 12 & 17 & & & & & 256 & 256 & 256 & 256 & & & & & 92 & 90 & 102 & 92 & & & & \\
\hline 32 & $\mathbf{F}$ & 60 & 4 & 40 & 20 & 23 & 26 & & & & & 2 & 2 & 2 & 2 & & & & & 80 & 81 & 86 & 85 & & & & \\
\hline 33 & $\mathbf{F}$ & 46 & 11 & 85 & 45 & 92 & 73 & & & & & 1024 & 1024 & 512 & 512 & & & & & 85 & 60 & 79 & 73 & & & & \\
\hline 34 & $\mathbf{F}$ & 51 & 27 & 45 & 12 & 7 & & & & & & 16 & 2 & 2 & & & & & & 72 & 86 & 91 & & & & & \\
\hline 35 & $\mathbf{F}$ & 75 & 4 & 31 & 40 & 30 & & & & & & 1024 & 1024 & 512 & & & & & & 66 & 75 & 78 & & & & & \\
\hline 36 & $\mathbf{F}$ & 42 & 1 & 11 & 7 & 4 & & & & & & 4 & 4 & 4 & & & & & & 85 & 87 & 95 & & & & & \\
\hline 37 & $\mathbf{M}$ & 66 & 7 & 57 & 46 & 22 & & & & & & 4096 & 4096 & 2048 & & & & & & 95 & 82 & 78 & & & & & \\
\hline 38 & $\mathbf{M}$ & 61 & 9 & 40 & 13 & 17 & & & & & & 256 & 32 & 32 & & & & & & 85 & 87 & 90 & & & & & \\
\hline 39 & $\mathbf{F}$ & 46 & 2 & 7 & 20 & 10 & & & & & & 128 & 128 & 32 & & & & & & 93 & 82 & 92 & & & & & \\
\hline 40 & $\mathbf{M}$ & 70 & 1 & 68 & 20 & 61 & & & & & & 128 & 256 & 256 & & & & & & 97 & 102 & 106 & & & & & \\
\hline 41 & $\mathbf{M}$ & 51 & 10 & 45 & 10 & 10 & & & & & & 512 & 256 & 512 & & & & & & 90 & 94 & 99 & & & & & \\
\hline 42 & $\mathbf{F}$ & 62 & 12 & 36 & 40 & 40 & & & & & & 1024 & 256 & 256 & & & & & & 94 & 92 & 94 & & & & & \\
\hline 43 & $\mathbf{M}$ & 69 & 5 & 116 & 84 & 73 & & & & & & 1024 & 1024 & 128 & & & & & & 70 & 86 & 91 & & & & & \\
\hline 44 & $\mathbf{M}$ & 63 & 5 & 62 & 58 & 30 & & & & & & 128 & 256 & 64 & & & & & & 62 & 58 & 73 & & & & & \\
\hline 45 & $\mathbf{F}$ & 75 & 7 & 64 & 50 & 22 & & & & & & 64 & 16 & 16 & & & & & & 64 & 50 & 69 & & & & & \\
\hline
\end{tabular}


and in five cases the patient became sero-negative after periods ranging from 3 to 21 months' treatment. The pattern of the Rose-Waaler in one patient is of particular interest since she acts as her own control (see below).

The requirements of other drugs, particularly analgesics and corticosteroids was recorded at each visit. Those patients with destructive arthritis did less well from this point of view than the others, in whom it was virtually the universal rule that the number of analgesic tablets could be markedly reduced or eliminated altogether. When penicillamine had been taken for about 6 months the amount of steroid was gradually reduced. As one might expect some patients were able to manage well without steroid, some did not and it was usually the patient who had been using the steroids from a time early in the development of his disease who tolerated withdrawal least well.

Eight patients were able to have their steroid completely withdrawn, twenty patients had a partial withdrawal, leaving eight in whom steroid could not be withdrawn. The regimen of each patient often included other anti-rheumatic drugs; these could be eliminated in many cases.

Changes in haemoglobin levels were recorded (Table 3). The results show that a rise occurred in twenty-nine patients $(70 \%)$ correlating well with those patients in whom the ESR fell. The average rise in haemoglobin was $10 \%$.

A standard form for the comparison of the ability of a patient to perform a wide range of activities was completed every 3 months using a scoring system of 2 points-task performed without difficulty; 1 point-task causes some difficulty but can still be done in spite of this; 0 points-task cannot be done. The total possible was 200 points. Using this system the mean results obtained are shown below.

\begin{tabular}{cccccc} 
Start & $\begin{array}{c}3 \\
\text { mths. }\end{array}$ & $\begin{array}{c}6 \\
\text { mths. }\end{array}$ & $\begin{array}{c}9 \\
\text { mths. }\end{array}$ & $\begin{array}{c}12 \\
\text { mths. }\end{array}$ & $\begin{array}{c}15 \\
\text { mths. }\end{array}$ \\
\hline 73 & 87 & 93 & 81 & 104 & 96
\end{tabular}

The assessments were undertaken by an experienced occupational therapist and were 'blind' as far as the regimen was concerned. The patients were not led into comparisons with their previous performances.

Rheumatoid nodules were, of course, seen often. The size of the nodules was noted; during the course of usually 6 months and often more, nodules could be seen to become softer and sometimes reduce in size, although none has completely disappeared. A similar pattern has been found in the size of the proximal IP joints, the size of which was measured at bi-monthly intervals with a set of jeweller's rings. The joint ring sizes decreased in many cases, usually by two or three rings.

We have been particularly impressed with the effect of penicillamine on the vascular lesions associated with rheumatoid disease.

Two middle-aged women were treated who had leg ulceration. In one the ulcers healed completely after 3 months having been present for 2 years and it was possible over this time to reduce her prednisolone dosage from $15 \mathrm{mg}$ daily to $6 \mathrm{mg}$ daily. In the other patient a substantial improvement occurred over 6 months. However, the ulcer is still not completely healed.

Three patients, all men, were treated who had nail-fold infarcts; in all, the infarcts have disappeared and have not recurred. A fourth man was treated who in 1968 developed rheumatoid disease with frank gangrene affecting the tip of one finger, the remaining fingers being cyanosed and cold. Following treatment with penicillamine the gangrenous patch sloughed off leaving a puckered scar. He has had no recurrence of gangrene and has normal circulation in his fingers.

Two patients in the series had symptoms of peripheral neuropathy. Both improved during treatment with penicillamine.

This is an uncontrolled trial but the following case report is thought worthy of mentioning as in a sense this patient acted as her own control.

A housewife, now aged 62 years, developed rheumatoid arthritis in 1963; she was given a course of gold which apparently led to remission for 3 years. In December 1966 her condition relapsed so that she could hardly walk with much early morning stiffness. A further course of gold was given without success. In June 1967 penicillamine was started 150 $\mathrm{mg}$ four times daily with gradual increase to $600 \mathrm{mg}$ four times daily. At the start of treatment the haemoglobin was $68 \%$, ESR $67 \mathrm{~mm} / \mathrm{hr}$ and Rose-Waaler $1: 512$.

Her condition satisfactorily improved so that after 6 months she was in virtually no pain and able to manage all household duties. The clinical improvement was accompanied by a gradual reduction of the Rose-Waaler titre which became negative in December 1967 when her haemoglobin was $86 \%$ and the ESR $14 \mathrm{~mm} / \mathrm{hr}$.

In January 1968 she developed nausea and dyspepsia thought to be due to penicillamine which was stopped. After a month she had become much worse; the DAT was 1:64 positive and the ESR 47 $\mathrm{mm} / \mathrm{hr}$. At her request penicillamine was again started: after 2 months the DAT was negative and the ESR $15 \mathrm{~mm} / \mathrm{hr}$. She has remained clinically well since April 1968 with persistently negative Rose-Waaler tests and ESRs. 


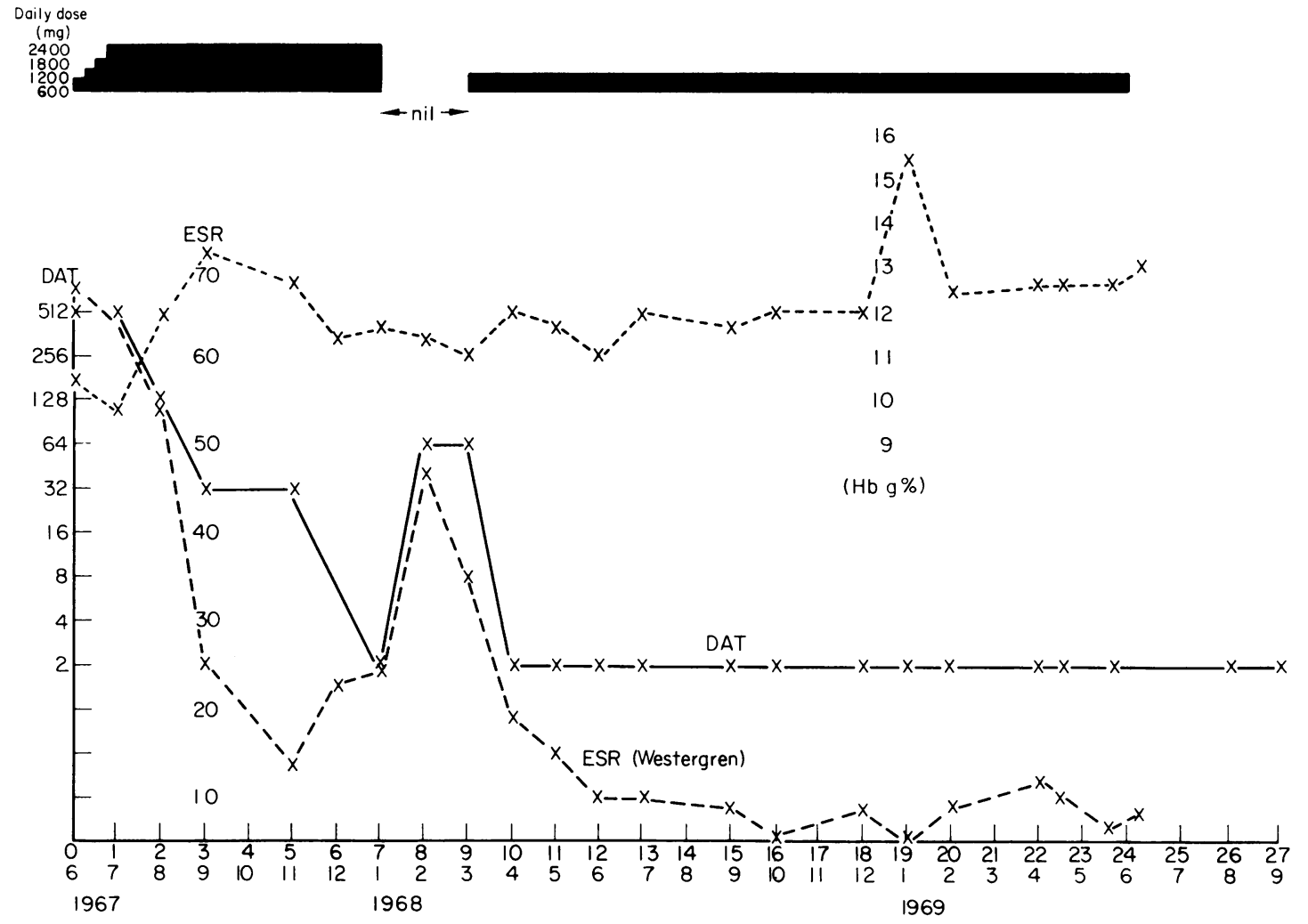

FIG. 2. Case report of Mrs M.L., housewife, acting as her own control.

In January 1970 the ESR was $5 \mathrm{~mm} / \mathrm{hr}$ and the haemoglobin $105 \%$.

Our clinical impression from these patients leads us to the conclusion that penicillamine has much to offer in the case of rheumatoid arthritis and it will be of especial interest to see how well this is borne out by the double-blind controlled trial which has been in progress during the past year.

\section{Side-effects}

The side-effects noted can be divided into those affecting the alimentary tract, the skin, kidneys and bone-marrow.

\section{Alimentary tract}

Many patients experienced either a soreness in the mouth or:

(a) Taste: A blunting of the sense of taste if the amount of penicillamine is increased too quickly or the total daily dose is too high. It was the case when we began to use the drug for it to be discontinued whenever the patient complained of losing his taste. It usually took between 2 and 3 weeks for taste to return, then only in infrequent cases was the trouble repeated later, then only in patients taking $1.8 \mathrm{~g}$ /day or more (12 capsules). It has already been stated that the maximum dose of penicillamine has been reduced to $300 \mathrm{mg}$ q.d.s. (8 capsules) and since this time there have been no cases of recurrent impairment of taste.

Early (i.e. when the dose is usually in the order of $600 \mathrm{mg} /$ day) loss of taste occurred in about $25 \%$ of patients. Seven months ago the high frequency of this distressing side-effect led us to add a small amount $(5 \mathrm{mg} /$ day) of copper sulphate to the regimen (Henkin et al., 1967; Jaffe, 1968).

No patient instituted on the drug has had complete lack of taste since then; two patients have had a blunting of taste lasting up to 2 weeks.

(b) Indigestion: Penicillamine has a characteristic taste, found unpleasant to some patients. Twenty percent of the patients in this series experienced dyspepsia, apparently unrelated to the dose. All patients were told to take the capsules after food or with milk but some still needed antacid occasionally. No patient has asked to be taken off the drug because of dyspepsia. No other symptom suggestive of peptic ulceration 
occurred. There were no instances of diarrhoea related to the capsules.

\section{Skin}

One patient who had previously been given gold injections and in whom a 'gold' rash occurred, developed a rash comparable in every way after having taken $600 \mathrm{mg}$ penicillamine daily for 6 weeks. The drug was discontinued and the rash faded over the next 3 weeks. There was no accompanying abnormal blood picture.

\section{Kidneys}

All patients in whom penicillamine was to be administered had a normal blood urea and no abnormality was found in their urine beforehand. The urine was examined for RBC, albumin and casts at monthly intervals.

Five cases of albuminuria were found-causes such as urinary tract infection, vaginal discharge/ menstruation having been excluded. Penicillamine was discontinued in all cases and three patients' urine became free after 10-14 days.

The fourth patient had persistant, minimal albuminuria for 3 months, without any rise in blood urea or evidence of a nephrotic syndrome. The urine then cleared spontaneously. The fifth patient developed gross albuminuria after having been on the drug for 8 months. Microscopy of the urine showed the presence of RBC and casts. The blood urea and serum proteins remained normal despite the prolonged albuminuria and subsequent renal biopsy was normal.

\section{Blood}

Particular note was taken of any lowering of the total WBC and platelet count. Four patients had a lowering of the platelet count to less than 150,000 - the minimum being 90,000 . In all four cases the count returned to normal within 2 weeks of stopping treatment, then the drug was cautiously reintroduced. No recurrence of the fall occurred; the dosage reached was $150 \mathrm{mg}$ less than the previous 'critical' level.

One patient developed agranulocytosis after 12 weeks at a dose of $2400 \mathrm{mg} /$ day. The patient made a complete recovery after the drug was discontinued. Two other patients' WBC fell to $2500 / \mathrm{mm}^{3}$ and became stable at that level, there being no clinical evidence of the bone-marrow depression. No mishap occurred when penicillamine therapy was reintroduced.

\section{Discussion}

Penicillamine has shown itself once more to be a preparation, the incidence of side-effects from which is high and not appearing at any particular stage during treatment. It is, therefore, of great importance that patients are kept under review regularly. Troublesome though the side-effects are, it is a rarity for the patient to be completely withdrawn from this treatment because of them: usually a lower maximum dose for that patient suffices.

Not every one of the patients treated in this series has benefited from penicillamine; indeed, one of the most intriguing factors was the unpredictability of its effect. The status of a group of patients observed for between 5 and 10 years is said to show that about $50 \%$ are either in remission or slightly better at the end of this period. Our figures for the patients who had had RA for up to 10 years show over $75 \%$ were improved during the 2 observed years. Of those having had the disease for more than 10 years, the overall improvement remained $75 \%$ against the 'expected' $30-35 \%$.

Objective assessment of the patients shows that $80 \%$ improved and these figures are high enough to warrant further examination of this form of treatment. It seems to us that patients with rheumatoid arteritis do particularly well and equally that patients with mutilating or destructive arthritis do not do well on this regimen, but we should like to emphasize that the results as a whole apply to a group of patients whose rheumatoid arthritis was worsening in spite of all conventional therapy.

One measure which one cannot communicate in terms of figures is a sense of well-being: the majority of these patients felt much better at the end of the 2 years than they did at the beginning-but this may well, of course, be due to the fact that they were receiving every possible care from the hospital, plus the sense of definitely 'belonging' since they were aware that the treatment was in some senses experimental.

This again emphasizes the value of the progressing double-blind trial.

The dose-regimen in this series would seem to be in some need of adjustment and possible future work might be based upon a quantity of penicillamine base per $\mathrm{kg}$ body weight rather than the present rather more crude method. This may in turn influence the frequency of side-effects.

\section{Acknowledgments}

The capsules of penicillamine hydrochloride (Distamine) used in this trial were provided through the courtesy of Dista Products Ltd. We would like to extend our thanks to Dr W. H. Lyle for his considerable help.

Also our thanks are due to Mrs Mavis Howarth for her untiring secretarial assistance.

\section{References}

Annals of Rheumatic Diseases (1962) Gold therapy in rheumatoid arthritis, $20,315$.

Asatoor, A.M. (1964) Pyridoxine deficiency in the rat produced by D-penicillamine. Nature, 203, 1382. 
Deutsch, H.P. \& Morton, J.I. (1957) Dissociation of human macroglobulins. Science, 125, 600.

Dressner, E. \& Trombly, O. (1960) Dissociation of the rheumatoid factor in vitro and in vivo. Clinical Research, $8,16$.

Golding, J.R., Wilson, J.V. \& Plunkett, T. (1968) Laboratory observations on the use of penicillamine in rheumatoid disease. Postgraduate Medical Journal, Supplement, Penicillamine, Oct. 1968, 40.

Griffen, S.W., UlloA, A., Henry, M., Johnston, M.L. \& Holley, H.L. (1960) Effect of penicillamine on circulating rheumatoid factor. Clinical Research, 8, 87.

Hartfall, S.J., Garland, H.G. \& Goldie, W. (1937) Gold treatment of arthritis. Lancet, ii, 838.
Henkin, R.I., Keiser, H.R., JafFe, I.A., Steknlieb, I. \& SCHEINBERG, I.H. (1967) Decreased taste sensitivity after D-penicillamine reversed by copper administration. Lancet, ii, 1268.

JAFFE, I.A. (1965) The effect of penicillamine on the laboratory parameters in rheumatoid arthritis. Arthritis and Rheumatism, 8, 1064

Jaffe, I.A., Altman, K. \& Merryman, P. (1964) The antipyridoxine effect of penicillamine in man. Journal of Clinical Investigation, 43, 1869.

JAFFE, I.A. (1968) Effects of penicillamine on the kidney and on taste. Postgraduate Medical Journal, Supplement, Penicillamine, Oct. 1968, 15. 